\title{
Invasiveness Index as a Predictor of Surgical Site Infection after Spinal Fusion, Revision Fusion, or Laminectomy - CORRIGENDUM
}

In the article by Hollenbeck, et al. ${ }^{1}$, Table 2 contains an error. The $P$ Value for Age in the "All Procedures" analysis should be 0.0162 , not 0.162 .

The authors apologize for this error.

\section{REFERENCE}

1. Hollenbeck BL, McGuire KJ, White AP, Yassa DS, Wright SB. Invasiveness index as a predictor of surgical site infection after spinal fusion, revision fusion, or laminectomy. Infect Control Hosp Epidemiol 2017;38:11-17. 